the scope and value of some of these discussions. However, there are two issues which are explored in some detail. Under the heading 'The Public's Right to Know' he considers the implications of the 1972 Nelson hearings Senate hearings which explored the extent of public dissemination of information about the risks of the Pill - and the media coverage of these hearings. He concludes that it is reasonable to link the public's right to know to the freedom of the press as long as this 'does not license the media to disseminate important information - especially that of a complex technical nature - irresponsibly and with little appreciation of the consequences'. Unfortunately he makes no suggestions about how such control of the media could be achieved!

Djerassi suggests that it was as a direct result of the Nelson hearings that all Pill packs (in Britain as well as in the US) now contain inserts specifying the Pill's side-effects. While applauding the principle of package inserts for all drugs, he rightly questions 'whether the legalistic manner in which the negative side-effects of the Pill are described in order to protect the manufacturer against possible liability is a helpful way to convey important information'.

The other issue runs right through the book - that is, how to balance the need to produce new contraceptive methods as rapidly as possible against the demand for the utmost safety. In Djerassi's view, the greater power of the Food and Drugs Administration (FDA), the development of consumer groups and an increasing fear of litigation have led to a shift in this balance, particularly in the US, such that the emphasis on safety has not only slowed down the development of new contraceptives but has made it increasingly unlikely that industries will consider even investing in any new development with so little prospect of profit. Clearly there is a need for government-funded (including internationally-based) research and fortunately some other countries are more willing to consider this than the US. According to Djerassi up till I 979 the US had still not contributed funds to the World Health Organisation's birth control programme.

Although Dierassi makes suggestions to encourage further research and innovation in the US, he does not claim that he can solve the basic dilemma of 'how to balance innovation with risk?'. Yet his own priority is clear and he states this as the reason for writing the book. 'In birth control, time is the most expen- sive commodity' and we do not have an unlimited amount of time.

DR JUDY BURY

Brook Advisory Centre Edinburgh

\section{Social Work with Undervalued Groups}

\author{
Ruth Wilkes \\ London, Tavistock Publications \\ £8.50 (paperback $£_{3.75)}$
}

Ruth Wilkes, in Social Work with Undervalued Groups, has made a stimulating and challenging contribution to the debate about values in social work, a subject which she believes is all too often neglected in favour of discussions about aims and methods.

Her thesis is that by making sociology and psychology rather than moral philosophy the underpinning of social work training we have shifted social work from its central value of concern for the individual, whoever he or she may be, towards a profession which manages and controls people's lives and fits them into the socially defined values of our time.

She examines two different justifications in moral philosophy for interfering in people's lives - notions of positive and negative freedom. Positive freedom is concerned with the realisation of one's 'true' self and justifies interference in the lives of others for their own good and for the good of society. Negative freedom is freedom from interference or freedom to do whatever you choose: interference in the lives of others is only justified in order to prevent harm to others or for self-protection.

Social work has unquestioningly adopted a base of positive freedom aiming as it does to do good and to perfect Man and society. Ruth Wilkes believes that social work should be based rather on a notion of negative freedom, that it should aim to avoid harm. She believes that the social worker should strive less to perfect methods and techniques which go to make the worker a more effective and purposeful manager and controller of people's lives, and more to understand the pain and suffering of each individual, to be receptive to his or her particular experience and to respond creatively with love, compassion and openmindedness.

We are asked to shift from the current analytic, empiricist approach to a metai physical one. This approach goes beyond what can be explained by socia conditioning or socially created values and norms to seeing each human bein as unique and infinitely resourceful in his search for harmony both withir himself and with the natural order.

I can recommend Ruth Wilkes brave and personal challenge to socig work to all those involved in it, but steeped in a positivist way of thinking as most of us are, it is not an easy book to read. It takes a leap of faith to embrace the metaphysical approach.

The author seems to suggest that social work is on the wrong track. How ever, I believe that it is possible to develop social work in Social Services Departments (which do undoubtedliy encourage a managerial approach), an at the same time develop more intuitive and creative forms of work in these and other agencies. With the development of specialties there is more and more interest in the old, the mentally and physically handicapped, and the sic and dying, all of whom the autho believes are undervalued in current practice.

The book is a timely reminder of limited power in the face of the sadiress of others, of the need to see end strengths in others, and of the needinot to believe that in social work we can of should control other people's lives.

CAROLINE POLMEA Lecturer in Social Work Bedford College London Universi

\section{Rights and Responsibilities in Modern Medicine}

\author{
Ed Marc D Basson \\ New York, Allan R Liss, Inc \\ $£_{15.00}$ DM66.00
}

This book is the second volume in series on ethics, humanism and medicine, and it consists of the proceeck ings of the I979-1980 conferences of those topics held at the University of Michigan, Ann Arbor. The participants at the conferences came from a variety of disciplines, such as various branche of medicine, law, theology, philosoph\$ and veterinary medicine, and it is a triv bute to them and their editor that theif disciplines provide backgrounds rathe 